\title{
Why this is not multiple sclerosis: a case based approach
}

\author{
Quando não é esclerose múltipla: abordagem baseada em casos \\ Zaira Fernanda Martinho Nicolau', Enedina Maria Lobato de Oliveira², Denis Bernardi Bichuetti
}

\begin{abstract}
Objective: To present a case series of patients previously diagnosed as multiple sclerosis (MS) which were later confirmed as an alternative diagnosis, and describe the clinical and paraclinical signs that led to this change. Method: Nine patients are described. We reviewed the patient's clinical chart, magnetic resonance images (MRI) and cerebrospinal fluid. Results: There was a mean of three typical symptoms of MS and four clinical red flags per patient. MRI red flags were found in $88,9 \%$ of all referrals, with a mean of 3 encountered per patient. Conclusion: We identified that, not only the misdiagnosed patients did not fulfill MS diagnosis criteria, but also how the described red flags are a useful tool in the differentiation of MS from other diseases. This data is important for guiding future diagnosis, especially for general clinicians and neurologists, which directly interfere with the patient's management, treatment, prognosis and quality of life.
\end{abstract}

Keywords: multiple sclerosis, diagnosis, clinical, MRI red flags.

\section{RESUMO}

Objetivo: Apresentar uma série de casos de pacientes previamente diagnosticados como esclerose múltipla (EM) que tiveram um diagnóstico final alternativo, e descrever os sinais clínicos e paraclínicos que levaram à esta mudança. Método: Nove pacientes encaminhados para confirmação diagnóstica de EM. Revisamos os prontuários, imagens de ressonância magnética (MRI) e líquido cefalorraquidiano. Resultados: Houve uma média de três sintomas típicos de EM e quatro sinais de alerta por paciente. Sinais de alerta de ressonância magnética foram encontrados em $88,9 \%$ dos casos, com média de 3 por paciente. Conclusão: Identificou-se que, não só os pacientes com diagnóstico incorreto não cumprem critérios de diagnóstico, mas também como os sinais de alerta já descritos são uma ferramenta útil na diferenciação de EM de outras doenças. Esta informação é importante para orientar a assertividade diagnóstica, especialmente para os clínicos e neurologistas gerais, com interferencia direta no tratamento, prognóstico e qualidade de vida do paciente.

Palavras-chave: esclerose múltipla, diagnóstico, clínico, ressonância magnética.

Multiple sclerosis (MS) is a chronic immune-mediated inflammatory disease that affects the central nervous system (CNS) and is the most frequent cause of non-traumatic neurologic disability in young and middle-age adults in specific communities ${ }^{1,2}$. The first symptoms usually appear between 20 and 40 years of age, affects more frequently women than $\mathrm{men}^{3}$, and has a greater incidence at the extremes of latitude ${ }^{4}$.

Early symptoms of MS are probably due to axonal demyelination, which leads to the slowing or blockade of neural conduction; and the resolution of the inflammatory edema associated to partial or total remyelination causes symptoms regression in the early years of the disease ${ }^{5}$. Most patients have a relapsing-remitting clinical course that can evolve to a secondary progressive phase within 15 to 20 years, and $15 \%$ present a slowly progressive disease without relapses ${ }^{6}$. Since some of the disease's symptoms are not specific and MS occurs at an age range that overlaps other autoimmune diseases, its differential diagnosis includes systemic and neurologic inflammatory conditions such as Lupus, Sjogren, Behcet and Susac's syndrome, to name a few, specific infectious diseases (HIV, hepatitis B and C and HTLV associated myelopathy), some metabolic and degenerative diseases, and, sometimes, primary and secondary neoplasms of the CNS, specially in progressive courses?

'Universidade Federal de São Paulo, Sao Paulo SP, Brazil;

${ }^{2}$ Universidade Federal de São Paulo, Disciplina de Neurologia, Sao Paulo SP, Brazil.

Correspondence: Denis Bernardi Bichuetti; Disciplina de Neurologia - UNIFESP; Rua Botucatu, 740; 04023-900 São Paulo SP, Brasil; E-mail: bichuetti@unifesp.br Conflict of interest: There is no conflict of interest to declare.

Disclosures: Bichuetti DB has received speaking/consulting honoraria from Bayer Health Care, Biogen Idec, Merck Serono, Genzyme-Sanofi and TEVA and had travel expenses to scientific meetings sponsored by Bayer Health Care, Merck Serono and TEVA. Oliveira EML has received speaking/consulting honoraria from Bayer Health Care, Biogen Idec, Merck Serono, Genzyme-Sanofi and TEVA and had travel expenses to scientific meetings sponsored by Bayer Health Care, Merck Serono and TEVA. Nicolau ZFM has nothing to disclose.

Received 30 April 2015; Received in final form 25 July 2015; Accepted 13 August 2015. 
The hallmark for any MS diagnostic criteria is the identification of CNS lesions disseminated in time and space, i.e., occurring in more than one site in different moments of one's lifetime, and this can be achieved with a combination of clinical and paraclinical exams ${ }^{8,9,10}$. A conceptual and objective framework for performing the differential diagnosis of MS does not exist, furthermore it can change from site to site, as infections and inflammatory diseases have different prevalence around the world ${ }^{11,12}$. Red flag is a term that denotes clinical or paraclinical signs that do not correspond to common MS findings, and can be divided into MRI and clinical red flags ${ }^{11,12,13}$.

The European MAGNIMS group defined, by consensus meetings, MRI red flags in the setting of clinically suspected MS, which suggest alternative diagnosis when present ${ }^{13}$. By the same methodology, and international data-driven and consensus-based diagnostic approach, presented a list of major, intermediate and minor clinical symptoms (neurological or not) that should raise suspicion against the diagnosis of $\mathrm{MS}^{12}$. All clinician caring for patients with MS must know and use these consensus statements to guide appropriate clinical, radiological, and/or laboratory tests that should be done to exclude alternative diagnoses to MS and guide adequate treatment.

The aim of this study was to analyze the clinical and paraclinical features of patients that were initially diagnosed with MS, but whom in fact had an alternative disease. This information is important to assist clinicians with cases of atypical MS clinical presentations, in which the treatment and prognosis depends upon a correct formulation of the diagnosis.

\section{METHOD}

The Neuroimmunology Clinic of the Universidade Federal de São Paulo (UNIFESP) is a public tertiary care center focused on caring for patients with multiple sclerosis and other demyelinating diseases, established in 1994, and located at Hospital São Paulo ${ }^{14}$. From 1994 to 2014 the clinic has evaluated 1.599 patients, including 988 with MS and 116 with neuromyelitis optica; the remaining 495 patients (31\% of all) harbored an alternative diagnosis. This last group comprises patients with vascular disease of the CNS, metabolic disorders, non-demyelinating inflammatory disease, infectious diseases, systemic clinical diseases, psychiatric or psychogenic disorders and functional symptoms ${ }^{14}$, that were first diagnosed or suspected to have MS and sent for our evaluation and follow-up. Some of these patients had obvious signs and symptoms against MS, but some demanded extra investigation to have a final and proper diagnosis established ${ }^{12,13,14}$.

We selected patients sent for evaluation and follow up at the clinic with a previously stated diagnosis of MS, which were reviewed by the staff and had an alternative final diagnosis and the exclusion of MS as the cause of their signs and symptoms, seen consecutively from 2010 to 2013. Patients with a clear evidence of exclusively vascular disease of the CNS (i.e., with more than 50 years old and classic vascular risk factors), patients that presented with predominant peripheral nervous system symptoms, psychological or psychiatric disease and metabolic or hormonal disorders were excluded from this study due to an obvious alternative diagnosis, thus not representing a diagnostic challenge. Patients with a final diagnosis of neuromyelitis optica were also excluded from this analysis, as they have a very distinct presentation to $\mathrm{MS}^{15,16}$. We reviewed each patient's clinical chart, MRI of the brain and spinal cord and cerebrospinal fluid (CSF) analysis to conduct a descriptive study of the signs and symptoms that led to an initial diagnosis of MS and further present each case's red flags that signaled the alternative diagnosis, based on previously published consensus statements ${ }^{11,12,13}$. When available, treatment options for each case are also described.

All patients included in this study took part in a prospective registry of inflammatory and demyelinating disease ongoing in our unit that was approved by the institutional ethic committee and each patient signed an informed consent form.

\section{RESULTS}

Nine patients that fulfilled the study's inclusion and exclusion criteria are described in this study (Table 1).

\section{Clinical data}

The mean age of symptom's onset was 34 years, six $(66.7 \%)$ patients were female and three $(3.3 \%)$ were male. Patients had been previously told they had MS for a mean of two years (Table 1). There was a mean of three typical symptoms and four clinical red flags per patient (Table 2).

\section{MRI data}

All patients had their MRI performed more than one time except patient six. The scans (Figures 1 to 3 ) were evaluated by the clinic's staff and neuroradiology team at each appointment and classified according diagnostic criteria for MS and the presence of radiological red flags (Table 2).

\section{Patient case examples}

The patients' summaries illustrate their chronological symptoms progression and conduct held to pursuit the correct diagnosis after the suspicion that the case was not MS. Each patient's final diagnosis is also organized in Tables 1 and 2.

\section{Patient 1}

At age 38 presented an acute episode of hypoesthesia, tetraparesis, sudden bilateral amaurosis, seizure and 

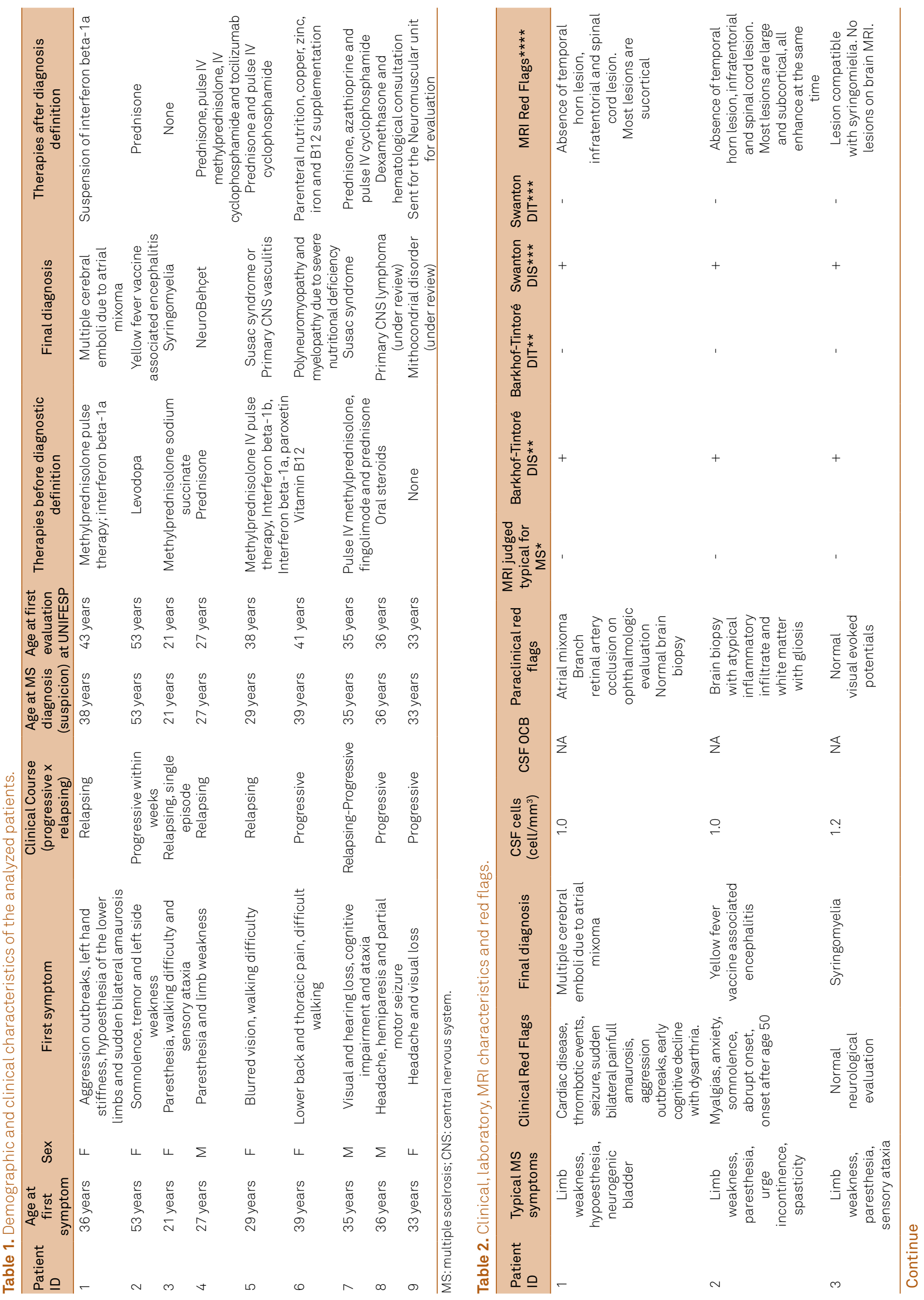


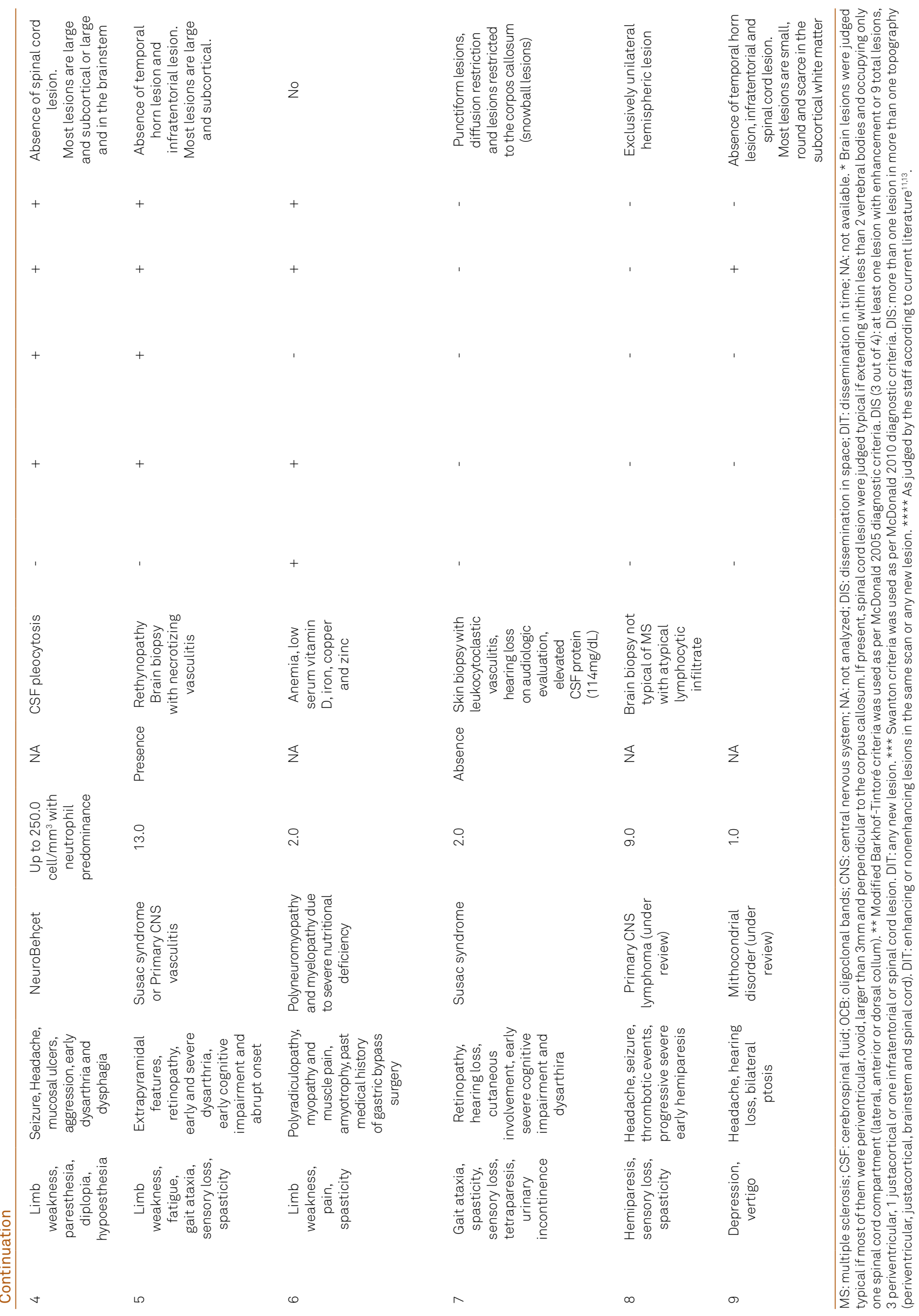




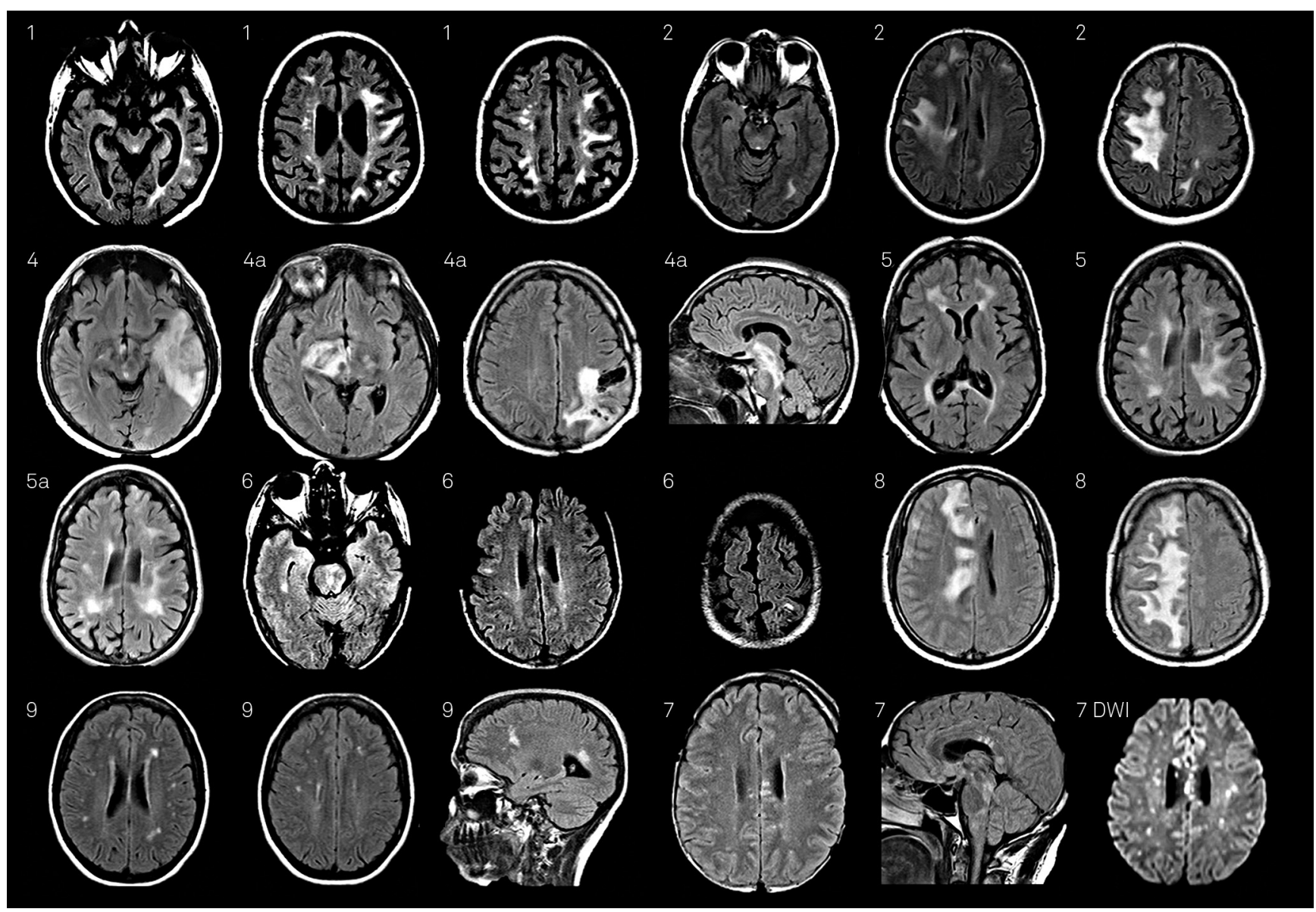

Numbers correspond to same patient on Table 1; images with letters are from the same patients at different time points. All are FLAIR images except image 7 DWI, which is a diffusion weighted image. Note that only patient 6 presents typical periventricular (including temporal horn) and justacortical multiple sclerosis lesions, all other images present at least one red flag as presented on Table 2.

Figure 1. Brain MRI from patients described on Table 1.

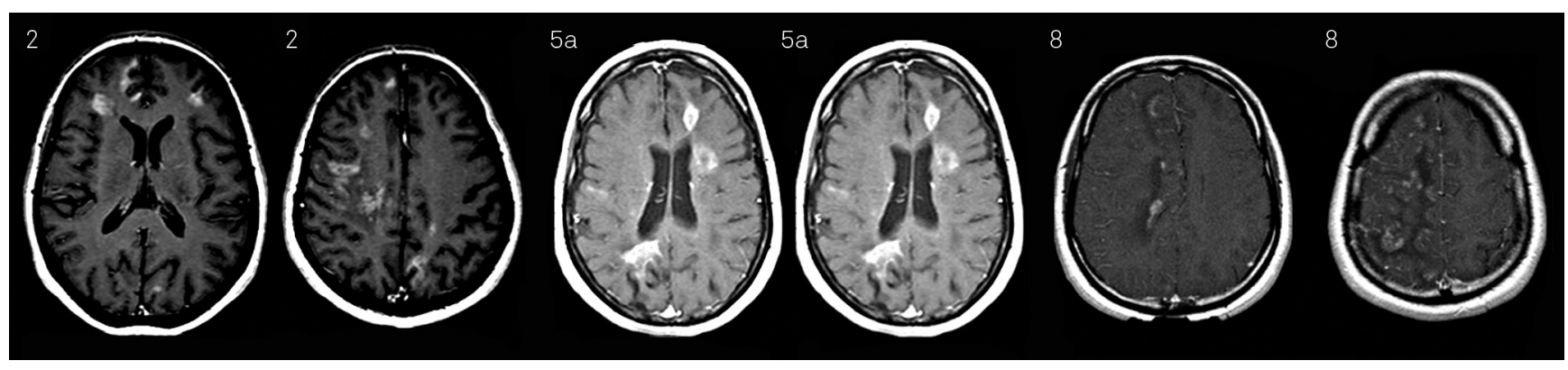

Numbers correspond to the same patients on Table 1 and exact same imaging time point as on Figure 1. Note that these images present a contrast enhancement pattern not typical for MS, thus representing red flags as discussed on Table 2.

Figure 2. T1 post gadolinium MRI from patients 2, 5 and 8.

aggression outbreaks, treated with pulse IV methylprednisolone and interferonbeta-1a. One year later she presented acute speech disturbances, right hemiparesis, vision loss and cognitive decline. She had been operated for a left atrial mixoma at 29 years-old.

After evaluation, her MRI lesions were judged to be of vascular origin (Figure 1) and her visual loss due to branch retinal artery occlusion. Her mixoma had recurred and she was sent for surgery for lesion removal; a brain biopsy excluded
CNS vasculitis and demyelinating lesion, thus confirming the diagnosis multiple cerebral emboli due to atrial mixoma.

\section{Patient 2}

At age 52 presented an episode of somnolence for $24 \mathrm{~h}$ followed by progressive left hemiparesis, tremor and urinary incontinence two weeks after being vaccinated for yellow fever and travelling to Costa Rica. Her MRI (Figures 1 and 2) disclosed large lesions with patchy enhancement even three 

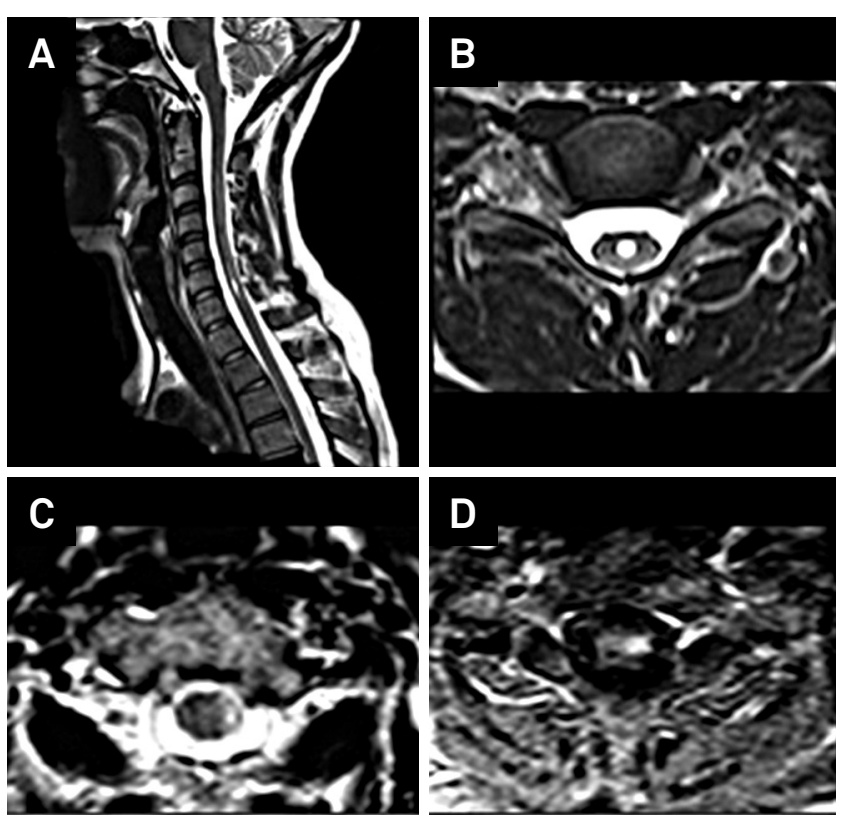

A: Sagittal T2 image disclosing central lesion without edema; B: axial T2 image disclosing this same lesion to be an enlargement of the central spinal canal (this lesion does not enhance); C: axial T2 image disclosing typical multiple sclerosis lesion in the lateral funiculum; D: axial T1 post gadolinium disclosing enhancement of the lesion shown in C.

Figure 3. Spinal cord images from patients 3 (top) and 6 (bottom).

months after vaccination. A brain biopsy was performed to discard CNS vasculitis, which disclosed mild inflammatory reaction. She was treated with IV and oral steroids with symptom's improvement, although, remained with mild neurological impairment on follow up, but without further clinical or MRI activity. Her final diagnosis remained a possible post vaccine acute demyelinating encephalomyelitis or vaccine encephalitis.

\section{Patient 3}

At age 24 presented left arm and legs paresthesis associated with mild sensory ataxia with progressive onset within a few days; she was an athlete of the handball university team. Her first MRI was judged to be compatible with demyelinating lesion and she was treated with pulse IV methylprednisolone with moderate improvement. She remained with occasionally upper limb paresthesis but presented no other symptoms three years later. Her MRI was reviewed and the lesion was concluded to be a cervical syringe (Figure 3 ).

\section{Patient 4}

At age 29 presented right progressive hemiparesis within weeks and partial motor seizure. A parietal mass lesion was operated and biopsy disclosed an inflammatory demyelinating lesion (Figure 1). On the following 10 months he presented recurrent episodes of left hemiparesis and somnolence with a brainstem and internal capsule lesion. Also, two episodes of fever and meningitis with neutrophils predominance but aseptic cultures, treated with steroids and antibiotics. His past medical history was reviewed and disclosed recurrent oral ulcers since he was a teenager, but no genital ulcers. His final diagnosis is a severe presentation of Neuro Behçet. He has failed immunosuppression with cyclophosphamide and tocilizumab and has currently been initiated on infliximab.

\section{Patient 5}

At age 29 presented acute painful bilateral blurred vision, arm and lower leg weakness, treated with steroids and started on interferon beta, which she used for nine years. On the subsequent years she presented recurrent episodes of neurological impairment, including dysarthria, dysphagia, hearing loss, ataxia and spasticity, all with sudden onset, leaving her with moderate to severe neurological impairment. Although she presented oligoclonal bands in the CSF and mild CSF pleocytosis on repetitive analysis; her MRI and clinical history where reviewed and judged not typical for MS. She was started on pulse IV cyclophosphamide but presented a new episode of multiple neurological deficits with increased number of brain lesions (Figure 1 and 2, image 5a). A brain biopsy was performed to rule out lymphoma and confirmed the diagnosis of necrotizing CNS vasculitis.

\section{Patient 6}

At age 39 she started a progressive course of muscle weakness and pain, muscle spasms and subtle left eye vision loss. Two years later she was bedbound, could not sustain herself seated without help, moderate tetraparesis but with mild hypereflexia, absence of Babinski sign, normal sensory exam, severe muscle pain on palpation and a Kwashiorkor physical appearance. She had performed a gastric bypass surgery 5 years before the symptoms started and was using only intramuscular vitamin B12 replacement therapy. Although her MRI (Figures 1 and 3) was judged compatible to MS, there were many clinical red flags (Table 2). Indeed, an extensive investigation disclosed multiple nutritional deficits and she improved with vitamin replacement therapy. One month later she presented moderate improvement, had mild muscle pain, could stand up with help and had resolution of generalized edema. Multiple nutritional deficiencies are known to cause central and peripheral neurologic injuries ${ }^{17}$, still, the patient was sent for further follow-up and MRI exams.

\section{Patient 7}

At age 35 presented progressive visual and hearing loss, cognitive difficulties, tetraparesis, gait ataxia and urinary incontinence for 3 months, associated to livedo reticularis. At first evaluation he was on prednisone associated to fingolimod for presumed MS. His complimentary investigation disclosed signs of systemic vasculitis and laboratory and MRI exams not compatible with MS (Table 2). He was started on pulse IV cyclophosphamide and later switched 
to oral azathioprine; 2 years later he presented mild cognitive deficit and moderate gait spasticity. Retinal angiofluorescein was normal, but only performed after intense immunosuppression.

\section{Patient 8}

At age 36 presented progressive left hemiparesis, headache and partial motor seizures. His MRI disclosed an extensive right side lesion with patchy enhancement (Figures 1 and 2) that presented marked improvement with IV steroids. He had a brain biopsy that disclosed normal results, but the lesion recurred upon steroids withdrawal. A second biopsy performed after a month without steroids was suggestive of central nervous system $\mathrm{T}$ cell lymphoma and he was sent for hematological evaluation and treatment.

\section{Patient 9}

This patient was referred to us at age 33 due to abnormal findings on MRI. She referred progressive visual loss since 16 years old due to Stargardt disease (juvenile onset macular degeneration, also present in her brother), depression, bilateral hearing loss and hypothyroidism. She was born to consanguineous parents (first degree cousins) and upon examination it was noted bilateral ptosis but no diplopia. She was sent to the neuromuscular unit for mitochondrial disease evaluation, which was considered the cause of her MRI lesions.

\section{Red flags in the diagnostic process}

MRI red flags were found in $89 \%$ of these referrals, with a mean of three red flags per patient, and only patient six presented typical MS lesions fulfilling imaging criteria. Clinical red flags can be rated as being of major, intermediate or minor significance in suggesting an alternative diagnosis to $\mathrm{MS}^{12}$. According to Miller's classification ${ }^{12}$, there were a total of $37 \%$ major, $13 \%$ intermediate and $8 \%$ minor clinical red flags among these patients. Other atypical symptoms, which are described as any non typical symptoms in the guideline from the International Panel on the diagnosis of $\mathrm{MS}^{8}$ and not specifically described in Miller's classification ${ }^{12}$, totalized $42 \%$ of all red flags.

\section{DISCUSSION}

The presence of neurologic symptoms compatible with MS, which can be mostly unspecific, or even radiological features common in this disease, should not be enough to narrow the clinician diagnoses hypothesis to only MS. To establish a correct diagnosis it is essential that the physician combine the patient's detailed past medical history, clinical findings, physical examination, MRI, laboratory tests and also take the known red flags into consideration ${ }^{12}$. Patients with a misdiagnosis may be injured by the use of inadequate therapies and consequently do not receive a proper management, declining ones clinical condition and quality of life ${ }^{18}$. The knowledge of the clinical course of MS and its clinical and paraclinical red flags are important since similar symptoms are reported in other diseases, such as neuromyelitis optica and acute disseminated encephalomyelitis, and even other inflammatory and vascular diseases, as depicted in this series.

Paraclinical tests are valuable tools for the diagnosis process of MS. MRI of the brain and spinal cord is the most sensitive investigational technique ${ }^{19}$ and the presence of imaging red flags can give important diagnostic hints ${ }^{13}$. The analysis of the MRI images should be meticulous and include the presence of specific characteristics, such as periventricular location with ovoid shape and perpendicular to the corpus callosum, dissemination in space and time ${ }^{8}$, and the correlation with the patient's clinical symptoms ${ }^{13,20,21}$. This last item is very important, since only MRI abnormalities are, up to date, no sufficient to establish one's diagnosis of MS, as neither Barkhof-Tintoré nor Swanton Criteria are 100\% specific $^{21,22}$. For instance, patient six had a compatible MRI, but when analyzed together with her clinical aspects, the diagnosis of MS was doubted.

The same thought should be held when analyzing the CSF. The presence of oligoclonal bands (OCB), which is common in patients with MS, should not be taken solely into consideration if specific clinical aspects of the disease are not present. Patient five had OCB bands, but her clinical symptoms were not clearly of MS, which lead to investigations that resulted in an alternative diagnosis. The CSF can thus add useful information about inflammatory and immunological alterations in patients with clinical presentation or radiological findings that are not typical of the disease ${ }^{8}$, but should also never be valued without paying attention to the patient's clinical presentation and MRI.

A whole-patient clinician approach is the most important attitude held by the physician, who should organize his medical reasoning by merging the clinical and paraclinical features, along with the proper identification of red flags, to succeed in diagnosing MS correctly. Isolated all these features are important, but their real significance is achieved only when they are analyzed together.

The limitations of our study are those of an observational cohort, thus not performed in a controlled setting. Furthermore, it was conducted within a western South-American population tertiary care hospital, thus the same study might yield distinct results or present other differential diagnosis if performed in other settings. Our aim is to expose to physicians faced with cases that appear to be MS that the existing guidelines on diagnosis of MS and the known red flags should be followed to perform an accurate diagnosis and minimize the chance of making a mistaken diagnosis and treatment, as this is important for each patient's management, treatment, prognosis and quality of life. 
1. Rodriguez M, Siva A, Ward J, Stolp-Smith K, O'Brien P, Kurland L. Impairment, disability, and handicap in multiple sclerosis: a population-based study in Olmsted County, Minnesota. Neurology. 1994;44(1):28-33. doi:10.1212/WNL.44.1.28

2. Hohlfeld R. Biotechnological agents for the immunotherapy of multiple sclerosis. Principles, problems and perspectives. Brain. 1997;120(5):865-916. doi:10.1093/brain/120.5.865

3. Compston A, Coles A. Multiple sclerosis. Lancet. 2002;359(9313):1221-31. doi:10.1016/S0140-6736(02)08220-X

4. Compston A. Risk factors for multiple sclerosis: race or place? J Neurol Neurosurg Psychiatry. 1990;53(10):821-23. doi:10.1136/jnnp.53.10.821

5. Noseworthy JH, Lucchinetti C, Rodriguez M, Weinshenker BG. Multiple sclerosis. N Engl J Med. 2000;343(13):938-52. doi:10.1056/NEJM200009283431307

6. Lublin FD, Reingold SC. Defining the clinical course of multiple sclerosis: results of an international survey. Neurology. 1996;46(4):907-911. doi:10.1212/WNL.46.4.907

7. Rolak LA, Fleming JO. The differential diagnosis of multiple sclerosis. Neurologist. 2007;13(2):57-72. doi:10.1097/01.nrl.0000254705.39956.34

8. McDonald WI, Compston A, Edan G, Goodkin D, Hartung HP, Lublin FD et al. Recommended diagnostic criteria for multiple sclerosis: guidelines from the International Panel on the diagnosis of multiple sclerosis. Ann Neurol. 2001;50(1):121-7. doi:10.1002/ana.1032

9. Polman CH, Reingold SC, Edan G, Filippi M, Hartung HP, Kappos $L$ et al. Diagnostic criteria for multiple sclerosis: 2005 revisions to the "McDonald Criteria". Ann Neurol. 2005;58(6):840-6. doi:10.1002/ana.20703

10. Polman $\mathrm{CH}$, Reingold SC, Banwell B, Clanet M, Cohen JA, Filippi $M$ et al. Diagnostic criteria for multiple sclerosis: 2010 revisions to the McDonald criteria. Ann Neurol. 2011;69(2):292-302. doi:10.1002/ana.22366

11. Kelly SB, Chaila E, Kinsella K, Duggan M, Walsh C, Tubridy N et al. Using atypical symptoms and red flags to identify non-demyelinating disease. J Neurol Neurosurg Psychiatry. 2012;83(1):44-8. doi:10.1136/jnnp-2011-300679

12. Miller DH, Weinshenker BG, Filippi M, Banwell BL, Cohen JA, Freedman MS et al. Differential diagnosis of suspected multiple sclerosis: a consensus approach. Mult Scler. 2008;14(9):1157-74. doi:10.1177/1352458508096878

13. Charil A, Yousry TA, Rovaris M, Barkhof F, De Stefano N, Fazekas F et al. MRI and the diagnosis of multiple sclerosis: expanding the concept of "no better explanation". Lancet Neurol. 2006;5(10):841-52. doi:10.1016/S1474-4422(06)70572-5

14. Bichuetti DB, Falcão AB, Boulos FC, de Morais MM, Lotti CB, Fragomeni $\mathrm{MO}$ et al. The profile of patients followed at the Neuroimmunology Clinic at UNIFESP: 20 years analysis. Arq Neuropsiquiatr. 2015;73(4):304-8. doi:10.1590/0004-282X20150004

15. Wingerchuk DM, Lennon VA, Pittock SJ, Lucchinetti CF, Weinshenker BG. Revised diagnostic criteria for neuromyelitis optica. Neurology. 2006;66(10):1485-9. doi:10.1212/01.wnl.0000216139.44259.74

16. Bichuetti DB, Oliveira EM, Souza NA, Tintoré M, Gabbai AA. Patients with neuromyelitis optica have a more severe disease than patients with relapsingremitting multiple sclerosis, including higher risk of dying of a demyelinating disease. Arq Neuropsiquiatr. 2013;71(5):275-9. doi:10.1590/0004-282X20130020

17. Hammond N, Wang Y, Dimachkie MM, Barohn RJ. Nutritional neuropathies. Neurol Clin. 2013;31(2):477-89. doi:10.1016/j.ncl.2013.02.002

18. Deisenhammer F, Rudick RA, Miller A. Multiple sclerosis or multiple possibilities: the continuing problem of misdiagnosis. Neurology. 2013;80(8):777. doi:10.1212/WNL.0b013e3182858cbc

19. Fazekas F, Barkhof F, Filippi M, Grossman RI, Li DK, McDonald WI et al. The contribution of magnetic resonance imaging to the diagnosis of multiple sclerosis. Neurology 1999;53(3):448-56. doi:10.1212/WNL.53.3.448

20. Aliaga ES, Barkhof F. MRI mimics of multiple sclerosis. Handb Clin Neurol 2014;122:291-316. doi:10.1016/B978-0-444-52001-2.00012-1

21. Barkhof F, Filippi M, Miller DH, Scheltens P, Campi A, Polman CH et al. Comparison of MRI criteria at first presentation to predict conversion to clinically definite multiple sclerosis. Brain. 1997;120(11):2059-69. doi:10.1093/brain/120.11.2059

22. Swanton JK, Rovira A, Tintore M, Altmann DR, Barkhof F, Filippi M et al. MRI criteria for multiple sclerosis in patients presenting with clinically isolated syndromes: a multicentre retrospective study. Lancet Neurol. 2007;6(8):677-86. doi:10.1016/S1474-4422(07)70176-X 